\section{Drug research: dead end or new horizon?}

Industrial drug research is facing a crisis. Higher investments are necessary for the discovery of fewer drugs, and the return on investment shrinks. ${ }^{12}$ Regulatory constraints ${ }^{3}$ and financial pressures ${ }^{4}$ have been blamed for slowing the development of new drugs at a time when truly new discoveries have become rare events. Among the new drugs established in recent years are the histamine $\mathrm{H}_{2}$-receptor antagonists, the angiotensin I converting-enzyme inhibitors, dopaminergics such as 2-bromocriptine, the anthelmintic praziquantel, and the monobactam antibiotics-not all that bad a record, and one that may well be compared with earlier periods considered teeming and prosperous. What has changed is the much larger expenditure, the incomparable higher cost, and the huge investments necessary to achieve these results.

One of the reproaches made to industrial drug research ${ }^{5}$ is that its efforts are concentrated on the common and chronic disorders while neglecting the rare diseases. Though understandable for economic reasons, such a one-sided research policy is medically undesirable. A second criticism is that drug research tends to be unimaginative, looking for quick results instead of waiting for the slowly ripening fruits of long-range projects. Both contain a core of truth. Drug research has arrived at a crossroads and has to decide where to go and how to proceed.

These matters were discussed at a recent symposium on "Decision Making in Drug Research" in Camogli, Italy, supported by the Fondazione Smith Kline, Milan. A group of research directors of multinational drug companies and representatives of universities and government institutions met for two days to discuss the problems of modern drug research. The methods of industrial drug research were seen to be in a state of fundamental change. Though not completely abandoned, the classical approach of screening of new chemicals now has only a small place. Chemical drug design has, however, not quite come up to expectations, its main shortcoming still being our modest insight into structureactivity relations.

One stimulating concept advanced at the meeting was an attempt to create new drugs by starting from a biological hypothesis and making use of new chemical substances to elucidate pharmacological or biological mechanisms. Such an integration of pathophysiological and pharmacological approaches may lead to new types of drugs. Systematic variation of known chemical structures should not, however, be deprecated as a means for the development of new drugs: talk of molecular manipulation or of me-too products is not justified in view of the advancements achieved by this approach.

One of the major problems for research-based pharmaceutical companies is attracting capable research people and keeping them intellectually satisfied. This is especially difficult when no products emanate from their efforts or when, for whatever reason, a research project or a whole section of research has to be abandoned. The answer may lie in close co-operation with university departments. A few examples have been encouraging, such as the one at Gothenburg, where local industry has supported the medical school and has been rewarded by efficient consultantship. The success of such ventures depends on an open-minded attitude from the company management and willingness from the academic partner.
External factors are having an increasing influence on decision making in drug research; political trends and government interventions, the power of press, television, and radio, and the attacks of pressure groups are directed not only against marketing and promotion but also against research activities. The drug industry has to face this challenge, even if the blame and accusations are often unjustified. Society is ready to condemn but reluctant to praise.

Meanwhile drug research continues to be productive. The opening of a new horizon makes us look for new ways and means to get there. We shall need to have the courage to undertake unorthodox procedures, to take responsibility for decisions, to assemble able groups of scientists, and to make proper use of their imagination and creativity. Efficient research will continue within the pharmaceutical industry, and important new drugs will be developed by systematic endeavour as well as by chance. The future cannot, however, be left to good fortune: it needs a comprehensive scientific approach to biomedical research.

F Gross

Chairman,

Department of Pharmacology,

University of Heidelberg,

6900 Heidelberg,

Federal Republic of Germany

${ }^{1}$ Gross F. Commentary: the present dilemma of drug research. Clin Pharmacol Ther 1976;19:1-10.

2 Weatherall M. An end to the search for new drugs? Nature $1982 ; 296$ : 387-90.

${ }^{3}$ Gross F. Constraints of drug regulation on the development of new drugs. Arch Toxicol 1979;43:9-17.

4 Smith T. The goose that lays the golden drugs. Br Med f 1980;281:1255-7.

${ }^{5}$ Gross F. The future of drug research-stagnation or progress ? Farmakoterapi 1977;33:1-18.

\section{Choosing treatment for metastatic breast cancer}

The choice of treatment for metastatic breast cancer is confusing and controversial and is made more difficult by the number of methods available. This wide choice reflects our failure to find any treatment that can cure established metastatic disease. (Though control of local recurrences may be a problem in some patients, in this article we look only at systemic treatments.)

Hormonal treatments have been used in breast cancer for nearly a century yet we still understand little of how breast cancer responds to hormones. The addition of oestrogens, progestogens, or androgens; the removal of hormones by ablation of the ovaries, adrenals, or pituitary; and the withdrawal of therapeutic doses of oestrogen may all cause regression of a tumour. In the past rules were drawn up for using these methods in a well-defined "cascade" of surgical and medical hormonal treatments. Yet the fact is that the addition or removal of oestrogens may cause the regression of a tumour in the same patient. The most useful innovation in recent years has been the introduction of hormone receptor assays. ${ }^{1}$ True, the results do not improve the survival of patients with breast cancer, but they are very helpful in selecting patients likely to respond to hormonal treatments. 
In addition to the likelihood of response to hormonal manipulation (best predicted by hormone receptor state) selection of treatment for metastatic disease depends on the efficacy and toxicity of hormone treatments and the activity and toxicity of available chemotherapy. In addition, the suitability of the individual patient for a particular treatment must always be borne in mind, as none of these treatments is curative, and all have side effects.

If the results of hormone receptor studies are negative then the initial treatment is usually with chemotherapy, since the chances of a response to a hormonal manoeuvre are very low (less than $5 \%)^{2}{ }^{2}$ The exceptions are elderly postmenopausal patients who are receptor-negative: they seem more likely to respond and, if frail, may benefit from a trial of hormonal treatment. If hormone receptor studies give positive results or cannot be done an initial hormonal treatment is usually indicated (one exception may be extensive liver metastases). The usual practice has been for an oophorectomy to be performed in premenopausal women and oestrogens to be used initially in the postmenopausal. Oophorectomy gives a $33 \%$ response rate in all patients ${ }^{3}$ and a $60-80 \%$ response rate in patients who have positive hormone receptors ${ }^{4}$ and is well tolerated-but the patient has to suffer the upset of an abdominal operation. The response rate from treatment with oestrogens in postmenopausal women ${ }^{3}$ is similar, though the correlation between response and hormone receptor state is rather less predictable in older women. Toxicity ${ }^{5}$ is common, and $10-15 \%$ of patients will stop treatment because of side effects. Patients who respond to an initial hormonal manoeuvre have a good chance of a further response, ${ }^{6}$ and premenopausal women who responded to oophorectomy and then relapsed have commonly then been treated by adrenalectomy or hypophysectomy. The response rate to these operations is similar ${ }^{3}$ to that of oophorectomy, but there is an increased morbidity and mortality. ${ }^{7}$ Androgens, progestogens, or adrenalectomy have been used in postmenopausal patients failing after a response to oestrogen, though toxicity is common. ${ }^{5}$

Two newish drugs, tamoxifen and aminoglutethimide, are being assessed to find their place in this complex cascade of hormonal treatments. Tamoxifen is an antioestrogen which probably acts by competing with oestrogen for receptors in the cancer cell $^{8}$ and comparisons with oophorectomy in premenopausal women suggest that the drug is as effective as surgery. ${ }^{9}$ Patients who respond to tamoxifen may also respond to subsequent oophorectomy, suggesting that the mechanism of action is more complicated than a simple antioestrogen effect. ${ }^{9}$ Trials of aminoglutethimide and prednisone, which block the adrenal production of steroid hormones and the conversion of androstanedione to oestrogen in peripheral tissues, ${ }^{10}$ show that they are as effective as adrenalectomy. ${ }^{11}$ Though tamoxifen has few significant toxic effects and is very well tolerated, ${ }^{12}$ aminoglutethimide is more toxic, with sedation and rashes as the principal side effects, though these will subside if treatment is continued. ${ }^{13}$ Some encouraging results from the use of aminoglutethimide in patients no longer responding to hormone treatment and chemotherapy have led to its use in patients relapsing from tamoxifen.

With the introduction of these two drugs the initial hormonal treatment of advanced breast cancer is changing. In premenopausal women tamoxifen may be used initially instead of oophorectomy and be followed, at relapse, by oophorectomy or aminoglutethimide, with progestogens, oestrogen, and androgens kept in reserve. In postmenopausal patients tamoxifen is now commonly used as the first treatment, since it is effective and well tolerated, later treatments for those relapsing being chosen from aminoglutethimide, progestogens, and oestrogens. The growing use of such sequences of hormonal treatment should mean that surgical hormonal manoeuvres will be needed less often. The predominant site of disease is becoming increasingly important for selection of the "best" treatment, though more detailed studies are needed to define the optimum treatment for disease which is mainly osseous, soft-tissue, hepatic, or pulmonary.

Chemotherapy should be reserved for patients who are hormone receptor-negative or who do not respond or stop responding to hormonal manoeuvres. Though response rates of about $50-70 \%$ can be achieved with combination chemotherapy, ${ }^{14}$ none of the patients are cured. Chemotherapy of this type produces serious toxicity, so that selection of patients and early assessment of the response and the overall usefulness of treatment are important. Preliminary studies ${ }^{15}$ of the combination of hormone treatment with chemotherapy have suggested that the disease-free period is prolonged, but further trials are needed before any conclusions can be drawn.

The choice of treatment in metastatic breast cancer does not lie between hormones and chemotherapy or indeed between one hormonal treatment and another. Many patients will respond to one or all of the treatments available, and the clinician needs to be able to select the appropriate sequence of treatments. The aim should be maximal tumour response, for as long as possible, with the minimal side effects. Although we cannot cure advanced disease, the accurate selection of the "best" treatment for individual patients remains a worthwhile goal.

Christopher Williams Senior lecturer and honorary consultant physician

CRC Medical Oncology Unit, Southampton General Hospital,

Southampton SO9 4XY; and

Combined Breast Clinic,

Royal South Hants Hospital,

Southampton SO9 4PE

ROGER BUCHANAN Consultant radiotherapist

Wessex Regional Radiotherapy Centre, and

Combined Breast Clinic,

Royal South Hants Hospital,

Southampton SO9 $4 \mathrm{PE}$

${ }^{1}$ Byar DP, Sears ME, McGuire WL. Relationship between estrogen receptor values and clinical data in predicting the response to endocrine therapy for patients with advanced breast cancer. Eur $\mathcal{F}$ Cancer 1979; $15: 299-310$.

${ }^{2}$ McGuire WB, Carbone PP, Sears ME, Escher GC. Estrogen receptors in human breast cancer: an overview. In: McGuire WL, Carbone PP, Vollmer EP, eds. Estrogen receptors in breast cancer. New York: Raven Press, 1975:1-9.

${ }^{3}$ Henderson IC, Canellos GP. Cancer of the breast: the past decade. $N$ Engl f Med 1980;302:17-30, 78-90.

- Legha SS, Davis HL, Muggia FM. Hormonal therapy of breast cancer: new approaches and concepts. Ann Intern Med 1978;88:69-77.

- Kennedy BJ, Nathanson IT. Effects of intensive sex steroid hormone therapy in advanced breast cancer. $\mathcal{F} A M A 1953 ; 152: 1135-41$.

- Kostraba N, Kiang D, Frenning D, Theolgides A, Kennedy BJ. Multiple endocrine therapy $(\mathbf{R x})$ in the management of advanced breast cancer. Proceedings of the American Association for Cancer Research 1980;21: 147. (Abstract.)

' Robin PE, Dalton GA. The role of major endocrine ablation. In: Stoll BA, ed. Breast cancer management-early and late. London: Heinemann Ltd, 1977.

${ }^{8}$ Heel RC, Brogden RN, Speight TM. Tamoxifen. A review of its pharmacological properties and therapeutic use in the treatment of breast cancer. Drugs 1978;16:1-24. 
- Pritchard KI, Thomson DM, Myers RE, Sutherland DJA, Mobbs BG, Meakin JW. Tamoxifen therapy in premenopausal patients with metastatic breast cancer. Cancer Treat Rep 1980;64:787-96.

${ }^{10}$ Fishman LM, Liddle GW, Island DP, Fleischer N, Küchel O. Effects of aminoglutethimide on adrenal function in man. $f$ Clin Endocrinol 1967;27:481-90.

11 Santen RJ, Worgul T, Veldhuis J, et al. Randomized, controlled trial of medical adrenalectomy with aminoglutethimide and surgical adrenalectomy. Proceedings of the American Association for Cancer Research $1980 ; 21: 410$. (Abstract.)

12 Mouridsen HT, Palshof T, Patterson J, Battersby L. Tamoxifen in advanced breast cancer. Cancer Treat Rev 1978;5:131-41.

13 Wells SA, Santen RJ, Lipton A, et al. Medical adrenalectomy with aminoglutethimide. Clinical studies in postmenopausal patients with metastatic breast carcinoma. Ann Surg 1978;187:475-84.

14 Bull JM, Tormey DC, Li S-H, et al. A randomized comparative trial of adriamycin versus methotrexate in combination drug therapy. Cancer 1978;41:1649-57.

${ }^{15}$ Rossof AH, Creech RH. Randomized evaluation of combination chemotherapy vs observation alone following response or stabilization after oophorectomy for metastatic breast cancer in premenopausal women. Proceedings of the American Association for Cancer Research 1980;21: 407. (Abstract.)

\section{Küntscher's nails for femoral fractures}

Though others had tried before him, ${ }^{1}$ it was Küntscher of Kiel who, at the beginning of the second world war, perfected intramedullary nailing for fractures of the shaft of the femur. ${ }^{2}$ $\mathrm{He}$ described a relatively elastic hollow nail, V-shaped or clover-leaf in section, inserted over a guide wire after careful reaming of the medullary cavity to the best size. The dramatic success of the method led to its early adoption in continental Europe $^{3} 4$ and, after the war, to its general use throughout the world. ${ }^{5}$ It is now a standard method of treatment.

In Küntscher's original "closed" technique the nail was inserted through a short incision over the greater trochanter and was passed down the femoral shaft under $x$-ray control. Nowadays the open, retrograde method has become the more popular. The fracture is exposed and the bone ends are prepared. A nail of the correct size is hammered home into the proximal fragment so that the top end emerges in the buttock, where it is found through a separate incision. The fracture is reduced and the nail is driven back down into the distal femur. The fixation obtained is much stronger than that from plates and screws and is usually enough to allow unprotected knee exercises and weight bearing within a few days-a great advantage in the elderly, for whom the alternative of prolonged traction in bed threatens a major ordeal. Nailing is indicated when there is a complicating fracture of the patella or tibia on the same side, or damage to a major blood vessel, or when a head injury is causing prolonged loss of consciousness. It may again be of advantage in pathological fractures, particularly those caused by metastases, where union may sometimes be slow, and when, with life running out, a prolonged period in hospital is unwelcome. Finally, medullary nailing is often an important part of the treatment of non-union of the femur.
The operation is best applied to fractures of the upper or middle thirds of the bone, where both fragments afford a good grip. Transverse or short oblique fractures are easiest to hold, though the ingenious and resourceful surgeon will often succeed even with spiral or comminuted injuries. When the circumstances are favourable medullary nailing may well be seen as the method of choice for femoral shaft fractures, and, indeed, there is much evidence in its favour. ${ }^{78}$ The decision will be affected by the surgeon's confidence in his asepsis, and it may with advantage be discussed with the patient. When there is no urgency, delaying the operation a week or two appears to reduce the chance of later failure of union. ${ }^{9}$

When the open technique is used the main anxiety arises from the-risk of introducing infection, which, when established deep in the bone, can cause prolonged invalidism and permanent disability. The safer "closed" technique, with an infection rate of less than $1 \%$, has recently received fresh support $^{10}$-and has certainly become easier and quicker now that the $x$-ray image intensifier is available for use in the operating theatre. Once inserted and free of infection the nail has few complications apart from a tendency to migrate, usually upwards so that the proximal end causes discomfort at the hip. Hunter"11 has pointed out that migration occurs more often than has been generally recognised; some movement occurs in as many as two out of three cases, though to an important extent much less often. The remedy is to replace the nail with a larger one, more firmly impacted. Migration stops when the fracture is united. A nail causing symptoms may then be removed, but the need to take out all Küntscher nails routinely is arguable.

A J Harrold*

Consultant Orthopaedic Surgeon,

St Mary's Hospital,

London $\mathbb{W} 21 \mathrm{NY}$

${ }^{*} \mathrm{Mr}$ Harrold died on 23 October, before he could correct the proofs of this article.

${ }^{1}$ Groves EWH. Ununited fractures, with special reference to gunshot injuries and the use of bone grafting. Br $\mathcal{F}$ Surg 1918-19;6:203-47.

${ }^{2}$ Küntscher G. Di Marknagelung von Knockenbruchen. Langenbeck's Archiv für Klinische Chirurgie vereinigt mit Deutsche Zeitschrift für Chirurgie $1940 ; 200: 443-9$.

${ }^{3}$ Soeur R. Intramedullary pinning of diaphyseal fractures. F Bone foint Surg 1946;28:309-31.

4 Böhler L. Medullary nailing of Küntscher. London: Baillière Tindall and Cox, 1948.

${ }^{5}$ Watson-Jones R, Adams JC, Bonnin JG, et al. Medullary nailing of fractures after fifty years. With a review of the difficulties and complications of the operation. $\mathcal{F}$ Bone foint Surg 1950;32B :694-729.

${ }^{6}$ Lloyd-Roberts GC. Intramedullary nailing in recent fractures of the femoral shaft. Lancet $1951 ; \mathrm{i}: 711-3$.

${ }^{7}$ Rokkanen $\mathrm{P}$, Slätis $\mathrm{P}$, Vankka E. Closed or open intramedullary nailing of femoral shaft fractures? A comparison with conservatively treated cases. $\mathcal{F}$ Bone foint Surg 1969;51B:313-23.

${ }^{8}$ Carr CR, Wingo $\mathrm{CH}$. Fractures of the femoral diaphysis. A retrospective study of the results and costs of treatment by intramedullary nailing and by traction and a spica cast. F Bone foint Surg 1973;55A:690-700.

${ }^{9}$ Lam SJ. The place of delayed internal fixation in the treatment of fractures of the long bones. F Bone foint Surg 1964;46B:393-7.

${ }^{10}$ Esser MP, Cloke JH, Hart JAL. Closed Küntscher nailing: a clinical review after 20 years. Injury 1982;13:455-9.

${ }^{11}$ Hunter SG. The migration of femoral Küntscher nails: a clinical study. Injury 1982;13:460-3. 